\title{
Carbazole-based sensitizers for potential application to dye sensitized solar cells
}

\author{
NARESH DUVVA $^{\mathrm{a}}$, RAVI KUMAR KANAPARTHI ${ }^{\mathrm{a}}$, JAIPAL KANDHADI ${ }^{\mathrm{a}}$, \\ GABRIELE MAROTTA $^{\mathrm{b}}$, PAOLO SALVATORI ${ }^{\mathrm{b}, \mathrm{c}}$, FILIPPO DE ANGELIS $^{\mathrm{b}, *}$ and \\ LINGAMALLU GIRIBABU ${ }^{\mathrm{a}, *}$ \\ ${ }^{a}$ Inorganic \& Physical Chemistry Division, CSIR-Indian Institute of Chemical Technology, \\ Hyderabad 500 007, India \\ ${ }^{\mathrm{b}}$ Computational Laboratory for Hybrid/Organic Photovoltaics (CLHYO), Istituto CNR di Scienze \\ Tecnologie Molecolari, Via Elce di Sotto 8, I-06123, Perugia, Italy \\ ${ }^{\mathrm{c}}$ D3-Computation, Istituto Italiano di Tecnologia, Via Morego 30, I-16163 Genova, Italy \\ e-mail: giribabu@iict.res.in; filippo@thch.unipg.it
}

MS received 6 May 2014; revised 8 September 2014; accepted 26 September 2014

\begin{abstract}
Two push-pull molecules employing carbazole and alkyl thiophene (CAR-THIOHX) or carbazole and triphenylamine (CAR-TPA) as donor moieties, with the cyanoacrylic group as the acceptor, have been designed and synthesized by simple organic transformations. Photophysical and electrochemical studies revealed the potential of these two systems in dye sensitized solar cells (DSSC). Under standard irradiation conditions, CAR-TPA and CAR-THIOHX exhibited 2.12 and $1.83 \%$ of overall power conversion efficiencies respectively. The moderate photovoltaic efficiency of the sensitizers has been attributed to the poor light absorption of the sensitizers in the visible region. Density functional theory (DFT) calculations have shown a strong intramolecular charge transfer character, with the HOMOs of both the sensitizers exclusively localized on the corresponding donor moieties and LUMOs on the cyanoacrylic acid acceptor. On the other hand, the calculated high dihedral angle between the carbazole donor and the phenyl bridge for these sensitizers impedes the conjugation along the dyes backbone, and thus leads to less extended and intense absorption spectra in the visible region.
\end{abstract}

Keywords. Sensitizer; metal-free; push-pull; carbazole; DFT.

\section{Introduction}

In recent years, metal-free organic materials, because of their unique optical and electronic properties, have been used quite extensively in optoelectronic devices which include solar cells. ${ }^{1-5}$ Dye sensitized solar cells' (DSSCs) research progressed immensely after the pioneering work of O'Regan and Grätzel on electrochemical cell which exhibited high power conversion efficiency using ruthenium(II) polypyridyl complexes. ${ }^{6}$ Among the various ingredients of the DSSC, the dye which sensitizes the $\mathrm{TiO}_{2}$ semiconductor, plays an important role in achieving high efficiency and durability of the cell. Although the ruthenium(II) based complexes are very promising in harvesting solar energy, they have certain drawbacks which turned the attention of the researchers towards metal-free organic dyes, porphyrins and other molecular systems. ${ }^{7}$ The metal-free organic dyes have the advantage of a large diversity in

*For correspondence the molecular structure and can be synthesized easily and rather inexpensively by following well-established design protocols. Moreover, it is possible to tune the absorption, fluorescence emission and electrochemical properties in a desired manner through suitable molecular design strategies for achieving better efficiency. More interestingly, the high molar extinction coefficients (up to $10^{5} \mathrm{M}^{-1} \mathrm{~cm}^{-1}$ ) of these metal-free sensitizers are particularly attractive. Among the various molecular architectures, donor- $\pi$-acceptor $(D-\pi-A)$ is found to show promising conversion efficiencies. So far, various electron donor moieties such as triphenylamine, carbazole, indoline, squaraines, etc., have been employed in the D- $\pi$-A architecture for designing efficient sensitizers. ${ }^{8}{ }^{8}$ Recently, a triphenylamine based sensitizer has shown outstanding power conversion efficiency of $10.3 \%$ by using $\mathrm{Co}(\mathrm{II} / \mathrm{III})$ redox couple. ${ }^{10}$ Over the past decade, molecular sensitizers based on triphenylamine, squaraine and indole have been well studied and documented. Carbazole is a heterocyclic aromatic system and its derivatives have been 
successfully employed in molecular electronics. ${ }^{11}$ However, carbazole based sensitizers have not progressed much compared to the aforesaid donor systems.

Miyasaka and co-workers employed a carbazole based polymer (poly(N-vinyl-carbazole)) for the first time in dye-sensitized solar cell as a hole transporting layer and the cell showed power efficiencies of 2.4 and $2.0 \%$ at 0.25 and 1 sun (AM 1.5) light irradiation, respectively. ${ }^{12}$ Since then, many efforts have been made to improve the efficiency and durability of the carbazole based DSSCs by following molecular engineering strategies. Koumura and co-workers reported a series of carbazole sensitizers for DSSCs and systematically investigated the effect of a $\pi$-conjugated system of n-hexyl-substituted oligothiophenes on the DSSC performances. ${ }^{13,14}$ A DSSC device fabricated from one of the derivatives showed overall power conversion efficiency of $7.7 \%$ under standard illumination conditions. Tan and co-workers reported a new sensitizer based on carbazole in which triphenylamine is used as auxiliary donor and the DSSC device showed efficiency as high as $7.03 \% .^{15}$ Recently, Han and coworkers reported efficient carbazole based sensitizer bearing flexible circle chain embracing $\pi$-spacer which has an efficiency of $9.2 \% .{ }^{16}$ In most of the carbazole sensitizers, cyanoacrylic acid group is commonly used as an anchoring group. However, Harima and co-workers reported new carbazole based sensitizers bearing pyridine anchoring group and achieved the efficiency of $1.61 \% .{ }^{17}$ By substituting proper functional groups at C3, C6 and N9 positions of the carbazole scaffold, one can tune the optoelectronic properties and thus the device performance. Recently, C2 and C7 positions have also been exploited in DSSCs to achieve excellent power conversion efficiencies $6.8-7.2 \% .^{18}$

Here, we report synthesis, characterization and device studies of two new carbazole derivatives, CARTHIOHX and CAR-TPA by exploiting alkyl substituted thiophene and triphenylamine at $\mathrm{C} 3$ and C6 positions as donor moieties (scheme 1). The CARTHIOHX consists of an anchoring group at N9 position and two hexyl substituted thiophene moieties at $\mathrm{C} 3$ and C6 positions of carbazole. In CAR-TPA, triphenylamine auxiliary donors have been covalently attached at $\mathrm{C} 3$ and C6, keeping the same anchoring group at N9 position. There are a few triphenylamine and indole based molecular sensitizers in which carbazole is used as auxiliary donors. ${ }^{19,20}$ Very recently, some of us have explored the possibility of using the carbazole moiety as an antenna donor in phenothiazine based dyes. ${ }^{21}$ However, very few carbazole sensitizers consist of auxiliary donor moieties. ${ }^{13}$ We believe that by substituting triphenylamine donor at C3 and C6 position, the electron

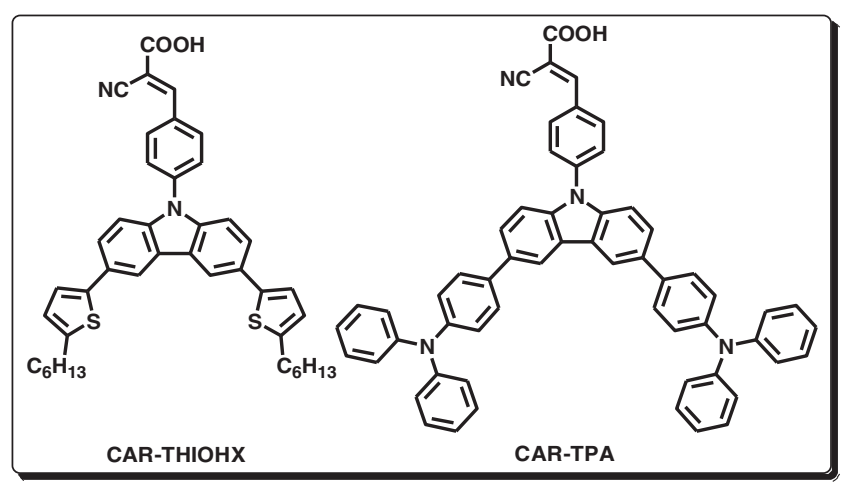

Scheme 1. Molecular structures of CAR-THIOHX and CAR-TPA.

density at N9 site can be enriched and hence the device performance. It is expected that the directional property of the excited dye further helps this new dye, CAR-TPA to have better electron flow from the triphenylamine to carbazole. Due to the enhanced electron donating ability of the triphenylamine moieties, CARTPA dye is expected to show better power conversion efficiency compared to the CAR-THIOHX.

\section{Experimental}

Triphenylamine, carbazole, bis(pinacolato)diborane, $\mathrm{N}$ bromosuccinamide (NBS), $\mathrm{Pd}\left(\mathrm{PPh}_{3}\right)_{2} \mathrm{Cl}_{2}$, pottasium acetate $(\mathrm{KOAc})$, pottasium tert-butoxide $(t-\mathrm{BuOK})$, cyanoacetic acid and ammonium acetate $\left(\mathrm{NH}_{4} \mathrm{OAc}\right)$ were procured from Sigma Aldrich and used as such. All solvents were procured from BDH (India) and dried wherever it is necessary prior to use. ${ }^{22}$ Analytical reagent grade solvents were used for synthesis and distilled laboratory grade solvents were used for chromatography. Milli-Q (Millipore) water was used for synthesis and purification. Silica gel (ACME, 100-200 mesh) was used for column chromatography and thinlayer chromatography (TLC) was performed by using precoated silica gel on aluminum plates (Merck, 60$\mathrm{F}_{254}$ ). Either gravity or flash chromatography was used for compound purification. Dual solvent system was eluted gradiently for the separation of reaction mixtures and the major intense band was collected and concentrated.

\subsection{Synthesis}

2.1a 4-Bromo triphenyl amine (1): Compound $\mathbf{1}$ was synthesized by following reported procedures with slight modifications. ${ }^{23,24}$ To a solution of triphenylamine $(2.1 \mathrm{~g}, 8.16 \mathrm{mmol})$ in $40 \mathrm{~mL} \mathrm{CCl}_{4}$, NBS $(1.6 \mathrm{~g}$, $8.16 \mathrm{mmol}$ ) was added and the reaction mixture 
refluxed for $4 \mathrm{~h}$ under nitrogen $\left(\mathrm{N}_{2}\right)$ atmosphere. During the reaction solid was formed which, conformed as succinimide. After filter the reaction mixture filtrate was evaporated and recrystalized from ethanol. Yield $93 \%$. ${ }^{1} \mathrm{H}$ NMR (500 $\mathrm{MH}_{\mathrm{Z}}, \mathrm{CDCl}_{3}$, TMS) $\delta(\mathrm{PPM}): 7.31(\mathrm{~d}$, $2 \mathrm{H}, J=8.4 \mathrm{~Hz}), 7.24(\mathrm{t}, 4 \mathrm{H}, \mathrm{J}=7.6 \mathrm{~Hz}), 7.07(\mathrm{~d}, 4 \mathrm{H}$, $J=8 \mathrm{~Hz}), 7.02(\mathrm{t}, 2 \mathrm{H}, J=7.5 \mathrm{~Hz}), 6.93(\mathrm{~m}, 2 \mathrm{H})$. ESI-MS: $m / z 323\left[\mathrm{M}^{+}\right]$.

2.1b N-(4-(4,4,5,5-Tetramethyl-1,3,2-dioxaborolan-2$y$ l)phenyl)- $N$-phenylbenzenamine (2): Compound $\mathbf{2}$ was synthesized according to the modified reported procedures. $^{25}$ 4-Bromo triphenylamine, 1 (0.32 g, $1 \mathrm{mmol})$, bis(pinacolato)diborane $(0.38 \mathrm{~g}, 1.5 \mathrm{mmol})$, KOAc $(0.4 \mathrm{~g}, 4 \mathrm{mmol})$ and $\mathrm{Pd}\left(\mathrm{PPh}_{3}\right)_{2} \mathrm{Cl}_{2}$ (35 mg, $0.05 \mathrm{mmol}$ ) were dissolved in minimum amount of degassed N,N-dimethyl formamide (DMF) in a $100 \mathrm{~mL}$ round bottom (RB) flask. Subsequently, the reaction mixture was subjected to reflux for $6 \mathrm{~h}$ under nitrogen atmosphere and the reaction was monitored by TLC. After completion of reaction, the solvent was evaporated under vacuum and crude compound was extracted with dichloromethane and concentrated using rotary evaporator. The crude compound was purified by column chromatography by employing silica gel as stationary phase and ethyl acetete:hexane (2:98) as eluting solvent. Yield $\sim 75 \%$. ${ }^{1} \mathrm{H}$ NMR (500 $\mathrm{MH}_{\mathrm{Z}}, \mathrm{CDCl}_{3}$, TMS) $\delta$ (PPM): 1.35(s, 12H), 7.05,(t, 4H, $J=7.99 \mathrm{~Hz}), 7.12(\mathrm{~d}$, $4 \mathrm{H}, J=7.99 \mathrm{~Hz}), 7.24-7.29(\mathrm{t}, 4 \mathrm{H}, J=6.9 \mathrm{~Hz}), 7.68$ $(\mathrm{d}, 2 \mathrm{H}, J=7.98 \mathrm{~Hz})$. ESI-MS: $m / z 371\left[\mathrm{M}^{+}\right]$.

2.1c 4-(9H-Carbazol-9-yl)benzaldehyde (3): Compound 3 was synthesized as per the reported procedure. ${ }^{26}$ In $50 \mathrm{~mL}$ RB flask, carbazole $(2.0 \mathrm{~g}$, $11.9 \mathrm{mmol})$ and $t$-BuOK $(1.33 \mathrm{~g}, 11.9 \mathrm{mmol})$ were dissolved together in DMF $(10 \mathrm{~mL})$ and heated at $110^{\circ} \mathrm{C}$ under stirring for $30 \mathrm{~min}$. 4-Fluorobenzaldehyde (1.5 g, $11.9 \mathrm{mmol}$ ) was taken in $5 \mathrm{~mL}$ of DMF and added dropwise to the reaction mixture over $30 \mathrm{~min}$. Then the reaction mixture refluxed for another $36 \mathrm{~h}$ at the same temperature under nitrogen atmosphere. After completion of the reaction, the reaction mixture was cooled to room temperature and poured in excess amount of ice-cold water $(700 \mathrm{~mL})$, from which solid precipitated. Then the solid was filtered under reduced pressure and dried. Finally, the crude compound was purified by column chromatography employing silica gel as stationary phase and $\mathrm{CHCl}_{3}$ : Hexane $(1: 1)$ as mobile phase. Yield $\sim 60 \%$. ${ }^{1} \mathrm{H}$ NMR $\left(500 \mathrm{MH}_{\mathrm{Z}}, \mathrm{CDCl}_{3}\right.$, TMS) $\delta(\mathrm{PPM}): 7.29-7.36(\mathrm{t}, 2 \mathrm{H}, J=6.798 \mathrm{~Hz}), 7.4-7.52(\mathrm{~m}$, $4 \mathrm{H}, J=8.30 \mathrm{~Hz}), 7.76-7.81(\mathrm{~d}, 2 \mathrm{H}, J=9.06 \mathrm{~Hz})$, 8.09-8.17(t, 4H, $J=7.54), 10.11(\mathrm{~s}, 1 \mathrm{H})$. ESI-MS: $m / z 271\left[\mathrm{M}^{+}\right]$. 2.1d 4-(3,6-Dibromo-9H-carbazol-9-yl)benzaldehyde (4): Compound 3 (1.60 g, $5.9 \mathrm{mmol})$ was dissolved in toluene $(10 \mathrm{~mL})$ and cooled to $0^{\circ} \mathrm{C}$ in an ice bath. Then a solution of NBS (2.60 g, $13.2 \mathrm{mmol})$ in DMF (15 mL) was added dropwise to the dissolved compound $\mathbf{3}$ and stirred for $30 \mathrm{~min}$. The reaction mixture was poured in ice-cold water and the obtained precipitate was filtered, washed with cold methanol for several times, and dried under reduced pressure. Yield $\sim 92 \%$. ${ }^{1} \mathrm{H}$ NMR (500 $\mathrm{MH}_{\mathrm{Z}}, \mathrm{CDCl}_{3}$, TMS) $\delta(\mathrm{PPM}): 7.3-7.53(\mathrm{~m}$, $4 \mathrm{H}, J=7.54 \mathrm{~Hz}), 7.74-7.79(\mathrm{dd}, 2 \mathrm{H}, J=8.3 \mathrm{~Hz})$, 8.07-8.3 (m, 4H, $J=8.4 \mathrm{~Hz}), 10.12$ (s, 1H). ESI-MS: $m / z 431\left[\mathrm{M}^{+}+\mathrm{H}\right]$.

\section{1e 4-(3,6-Bis(4-(diphenylamino)phenyl)-9H-}

carbazol-9-yl)benzaldehyde (5): Compound 5 was synthesized by palladium catalyzed Suzuki coupling between compound $\mathbf{4}$ and compound $\mathbf{2}$. In a typical synthesis, compound $4(0.22 \mathrm{~g}, 0.48 \mathrm{mmol})$, compound $2(0.53 \mathrm{~g}, 1.43 \mathrm{mmol})$, KOAc $(0.43 \mathrm{~g}, 3.84 \mathrm{mmol})$ and $\mathrm{Pd}\left(\mathrm{PPh}_{3}\right)_{2} \mathrm{Cl}_{2}(0.05 \mathrm{mmol})$ were dissolved in DMF and degassed for $30 \mathrm{~min}$. Then the reaction mixture was subjected to heat at boiling point of the solvent for $6 \mathrm{~h}$ under $\mathrm{N}_{2}$ atmosphere and the reaction was monitored by TLC. After completion of the reaction, the solvent DMF was evaporated, extracted from dichloromethane and water mixture. Then the finally obtained crude compound was purified by column chromatography on silica as stationary phase and $\mathrm{CHCl}_{3}$ : Hexane $(3: 7)$ as eluting solvent. Yield $\sim 75 \% .{ }^{1} \mathrm{H}$ NMR $\left(500 \mathrm{MH}_{\mathrm{Z}}\right.$, $\left.\mathrm{CDCl}_{3}, \mathrm{TMS}\right) \delta$ (PPM): 7.00-7.08 (t, 4H, = 7.176), 7.13-7.3 (m, 20H, $J=8.309 \mathrm{~Hz}), 7.53-7.69(\mathrm{~m}, 8 \mathrm{H}$, $J=8.687 \mathrm{~Hz}), 7.81-7.87(\mathrm{~d}, 2 \mathrm{H}, J=8.309 \mathrm{~Hz})$, $8.12-8.18(\mathrm{~d}, 2 \mathrm{H}, J=8.34 \mathrm{~Hz}), 8.35(\mathrm{~d}, 2 \mathrm{H}, J=1.32$ $\mathrm{Hz}), 10.12(\mathrm{~s}, 1 \mathrm{H}) . \mathrm{IR}\left(\mathrm{KBr}, \mathrm{cm}^{-1}\right): 2952,2854$ (alkyl $\left.v_{\mathrm{C}-\mathrm{H}}\right), 1645\left(v_{\mathrm{S}}, v_{\mathrm{C}=\mathrm{O}}\right) \quad 1451,1230$, 751. ESI-MS: $m / z 757\left[\mathbf{M}^{+}\right]$.

$2.1 \mathrm{f} \quad 4-(3,6-B i s(5-h e x y l t h i o p h e n-2-y l)-7,8$-dihydrocarbazol-9-yl)benzaldehyde (6): Compound 6 was synthesized by Suzuki coupling reaction of compound 4. In a typical synthesis compound $4(0.3 \mathrm{~g}, 0.7 \mathrm{mmol})$ and 5-hexylthiophene-2-yl-2-boronic acid (0.3 g, $1.404 \mathrm{mmol}$ ) were dissolved in dimethoxyethane, DME $(12 \mathrm{~mL})$ to which $\mathrm{Na}_{2} \mathrm{CO}_{3}$ solution $(2 \mathrm{M}, 5 \mathrm{~mL}$ of), $\mathrm{Pd}\left(\mathrm{PPh}_{3}\right)_{4}(0.1 \mathrm{mmol})$ were added and reaction mixture was degassed for $30 \mathrm{~min}$. The reaction mixture was then refluxed for $18 \mathrm{~h}$ under $\mathrm{N}_{2}$ atmosphere. After completion of the reaction (monitored by TLC), excess water was added to the reaction mixture, extracted with dichloromethane, organic layer separated and concentrated on rotary evaporator. Crude solid compound 
was purified by column chromatography using silica gel as stationary phase and ethyl acetate:hexane (1:10) as eluting solvent. Yield $\sim 70 \%$. ${ }^{1} \mathrm{H}$ NMR $\left(500 \mathrm{MH}_{\mathrm{Z}}\right.$, $\left.\mathrm{CDCl}_{3}, \mathrm{TMS}\right) \delta(\mathrm{PPM}): 0.76-0.88(\mathrm{t}, 6 \mathrm{H}, J=6.798$ $\mathrm{Hz}), 1.12-1.4(\mathrm{~m}, 12 \mathrm{H}, J=3.022), 1.51-1.71(\mathrm{~m}, 4 \mathrm{H}$, $J=7.554 \mathrm{~Hz}), 2.69-2.79(\mathrm{t}, 4 \mathrm{H}, J=7.554 \mathrm{~Hz}), 6.67$ $(\mathrm{d}, 2 \mathrm{H}, J=3.77 \mathrm{~Hz}), 7.05(\mathrm{t}, 2 \mathrm{H}, J=3.77 \mathrm{~Hz}), 7.28$ $(\mathrm{d}, 2 \mathrm{H}, J=8.30 \mathrm{~Hz}), 7.46-7.53(\mathrm{dd}, 2 \mathrm{H}, J=1.51$ $\mathrm{Hz}), 7.56-7.62(\mathrm{~d}, 2 \mathrm{H}, J=8.30 \mathrm{~Hz}), 7.91-8.00(\mathrm{~d}$, $2 \mathrm{H}, J=3.77 \mathrm{~Hz}), 8.15(\mathrm{~d}, 2 \mathrm{H}, J=1.51 \mathrm{~Hz}), 9.96$ (s, 1H). IR (KBr, cm $\left.{ }^{-1}\right)$ : 2897 (alkyl $\left.v_{\mathrm{C}-\mathrm{H}}\right), 1796\left(v_{\mathrm{S}}\right.$, $\left.v_{\mathrm{C}=\mathrm{O}}\right) 1449,1179,732$. ESI-MS: $\mathrm{m} / \mathrm{z} 604\left[\mathrm{M}^{+}\right]$.

2.1g CAR-TPA: Finally the desired compound, CAR-TPA sensitizer was synthesized by following Knoevenagel reation procedure. ${ }^{27}$ Compound 5 ( $0.76 \mathrm{~g}$, $1 \mathrm{mmol})$, cyanoacetic acid $(0.43 \mathrm{~g}, 5 \mathrm{mmol})$ and ammonium acetate $(0.24 \mathrm{~g}, 3 \mathrm{mmol})$ were dissolved in acetic acid $(10 \mathrm{~mL})$ and refluxed for $14 \mathrm{~h}$ under nitrogen atmosphere. The reaction was monitored by TLC and at the end of reaction, the reaction mixture poured in ice-cold water and extracted with chloroform. Collected organic layers were evaporated and dried. Then the obtained solid compound was purified by column chromatography using silica gel, stationary phase and $\mathrm{MeOH}: \mathrm{CHCl}_{3}(1: 10)$ as eluting solvent. Yield $\sim 76 \%$. Elemental analysis of $\mathrm{C}_{58} \mathrm{H}_{40} \mathrm{~N}_{4} \mathrm{O}_{2}$ (calculated mass \% in parentheses): $\mathrm{C}, 84.40$ (84.44); H, 4.90 (4.89); N, 6.80 (6.79). ${ }^{1} \mathrm{H}$ NMR (500 $\mathrm{MH}_{\mathrm{Z}}, \mathrm{CDCl}_{3}$, TMS) $\delta(\mathrm{PPM}): 7-7.1$ (t, $\left.4 \mathrm{H}, J=7.176\right)$, 7.13-7.3 (m, 20H, $J=8.309 \mathrm{~Hz}), 7.4-7.69(\mathrm{~m}, 8 \mathrm{H}$, $J=8.687 \mathrm{~Hz}), 7.81-7.87(\mathrm{~d}, 2 \mathrm{H}, J=8.309 \mathrm{~Hz})$, $8.12-8.18(\mathrm{~d}, 2 \mathrm{H}, J=8.34 \mathrm{~Hz}), 8.35(\mathrm{~d}, 2 \mathrm{H}, J=1.32$ $\mathrm{Hz}), 8.34$ (s, 1H). IR $\left(\mathrm{KBr}, \mathrm{cm}^{-1}\right): 3415\left(v_{\mathrm{O}-\mathrm{H}}\right) 2926$, 2854 (alkyl $\left.v \mathrm{C}_{-\mathrm{H}}\right), 2220\left(v_{\mathrm{S}}, v_{\mathrm{C} \equiv \mathrm{N}}\right), 1728\left(v_{\mathrm{S}}, v_{\mathrm{C}=\mathrm{O}}\right)$, 1454, 1276, 747. ESI-MS: $m / z 845\left[\mathrm{M}^{+}+\mathrm{Na}\right]$.

2.1h CAR-THIOHX: This compound was synthesized as per the procedure adopted for preparing CARTPA. Elemental analysis of $\mathrm{C}_{42} \mathrm{H}_{42} \mathrm{~N}_{2} \mathrm{O}_{2} \mathrm{~S}_{2}$ (calculated mass\% in parentheses): C, 75.21 (75.19); H, 6.30 (6.31); N, 4.20 (4.18). ${ }^{1} \mathrm{H}$ NMR (500 $\mathrm{MH}_{\mathrm{Z}}, \mathrm{CDCl}_{3}$, TMS) $\delta$ (PPM): 0.80-0.91(t, $6 \mathrm{H}, J=6.798 \mathrm{~Hz}), 1.1-$ $1.4(\mathrm{~m}, 8 \mathrm{H}), 1.54-1.69(\mathrm{~m}, 4 \mathrm{H}, J=6.798), 2.67(\mathrm{~s}, 4 \mathrm{H})$, $2.85(\mathrm{~s}, 4 \mathrm{H}), 7.28-7.39(\mathrm{dd}, 5 \mathrm{H}, J=5.85 \mathrm{~Hz}), 7.46-$ $7.83(\mathrm{~m}, 5 \mathrm{H}, J=8.49), 8.06-8.26(\mathrm{dd}, 4 \mathrm{H}, J=8.68$ $\mathrm{Hz}), 8.35(\mathrm{~s}, 1 \mathrm{H})$. IR $\left(\mathrm{KBr}, \mathrm{cm}^{-1}\right): 3406\left(v_{\mathrm{O}-\mathrm{H}}\right) 2926$, $2852\left(\right.$ alkyl $\left.v_{\mathrm{C}-\mathrm{H}}\right), 2217\left(v_{\mathrm{S}}, v_{\mathrm{C} \equiv \mathrm{N}}\right) 1624\left(v_{\mathrm{S}}, v_{\mathrm{C}=\mathrm{O}}\right), 1598$, 1514, 1362, 1227, 794. ESI-MS: $m / z 670\left[\mathrm{M}^{+}\right]$.

\subsection{Instrumentation}

${ }^{1} \mathrm{H}$ NMR spectra were recorded on a Brucker 300 Avance NMR spectrometer $(300 \mathrm{MHz})$ using PC controlled X-WIN software. The elemental analysis was carried out on Elementar, Vario MICRO CUBE analyzer. Cyclic voltammetric (CV) measurements were performed on a $\mathrm{PC}$-controlled $\mathrm{CH}$ instruments (CHI 620C electrochemical analyzer). For all measurements, $1 \mathrm{mM}$ solution of compounds in $\mathrm{CH}_{2} \mathrm{Cl}_{2}$ solvent were used at scan rate of $100 \mathrm{mV} / \mathrm{s}$ in which $0.1 \mathrm{M}$ tetrabutyl ammonium perchlorate (TBAP) is used as supporting electrolyte. The working electrode is glassy carbon, standard calomel electrode (SCE) is reference electrode and platinum wire served as auxiliary electrode. After a cyclic voltammogram (CV) had been recorded, ferrocene was added, and a second voltammogram was measured. The optical absorption spectra were recorded on a Shimadzu (Model UV-3600) spectrophotometer. Concentrations of solutions are ca. to be $1 \times 10^{-6} \mathrm{M}$ in all solvents. Steady-state fluorescence spectra were recorded on a Fluorolog-3 spectrofluorometer (Spex model, Jobin Yvon) for solutions with optical density at the wavelength of excitation $\left(\lambda_{\text {ex }}=\right.$ $350 \mathrm{~nm}) \approx 0.05$. Fluorescence quantum yields $(\phi)$ were estimated by integrating the fluorescence bands of the each individual compounds and comparing with standard quinine sulfate fluorescence emission $(\phi=$ 0.577 in $0.1 \mathrm{M} \mathrm{H}_{2} \mathrm{SO}_{4}$ ). Fluorescence lifetime measurements were carried on a picosecond time-correlated single photon counting (TCSPC) setup (FluoroLog3Triple Illuminator, IBH Horiba Jobin Yvon) employing a picosecond light emitting diode laser (NanoLED, $\lambda_{\text {ex }}=405 \mathrm{~nm}$ ) as excitation source. The decay curves were recorded by monitoring the fluorescence emission maxima of the triads $\left(\lambda_{\mathrm{em}}=430 \mathrm{~nm}\right)$. Photomultiplier tube (R928P, Hamamatsu) was employed as the detector. The lamp profile was recorded by placing a scatterer (dilute solution of Ludox in water) in place of the sample. The width of the instrument response function (IRF) was limited by the full width at half maxima (FWHM) of the excitation source, $\sim 625 \mathrm{ps}$ at $405 \mathrm{~nm}$. Decay curves were analyzed by non-linear least-squares iteration procedure using IBH DAS6 (version 2.3) decay analysis software. The quality of the fits was judged by the $\chi^{2}$ values and distribution of the residuals.

\subsection{Cell fabrication}

FTO glass (TEC-15, $2.2 \mathrm{~mm}$ thickness, Solaronix) was used for transparent conducting electrodes. The substrate was first cleaned in an ultrasonic bath using a detergent solution, acetone and ethanol respectively (each step $15 \mathrm{~min}$ long). The FTO glass plates were immersed into a $40 \mathrm{mM}$ aqueous $\mathrm{TiCl}_{4}$ solution at $70^{\circ} \mathrm{C}$ for $30 \mathrm{~min}$ and washed with water and ethanol. Two 
kind of $\mathrm{TiO}_{2}$ film were tested: a monolayer of opaque $\mathrm{TiO}_{2}$ paste (Dyesol, 18NR-AO), or a layer of transparent $\mathrm{TiO}_{2}$ paste (Dyesol, 18NR-T) coated by a scattering layer (Dyesol, WER 2.0), spread on the FTO glass plates by doctor blade. The $\mathrm{TiO}_{2}$ layer films were treated in an ethanol chamber and dried for 5 min at $120^{\circ} \mathrm{C}$. The $\mathrm{TiO}_{2}$ coated electrodes (active area $0.2 \mathrm{~cm}^{2}$ ) were gradually heated under air flow at $325^{\circ} \mathrm{C}$ for $5 \mathrm{~min}$, at $375^{\circ} \mathrm{C}$ for $5 \mathrm{~min}$, at $450^{\circ} \mathrm{C}$ for $15 \mathrm{~min}$, and $500^{\circ} \mathrm{C}$ for $15 \mathrm{~min}$. After the sintering process, the $\mathrm{TiO}_{2}$ film was again treated with $40 \mathrm{mM} \mathrm{TiCl} 4$ solution, then rinsed with water and ethanol. The electrodes were heated at $500^{\circ} \mathrm{C}$ for $30 \mathrm{~min}$ and after cooling $\left(80^{\circ} \mathrm{C}\right)$ were immersed for 6 hours into sensitizing bath. This consisted of EtOH:THF $=9: 1$ solutions of dyes in $0.2 \mathrm{mM}$ concentration, with $10.0 \mathrm{mM}$ of $3 \mathrm{a}, 7 \mathrm{a}-$ dihydroxy-5b-cholic acid (CDCA) added. Counter electrodes were prepared by coating with a drop of $\mathrm{H}_{2} \mathrm{PtCl}_{6}$ solution ( $2 \mathrm{mg}$ of Pt in $1 \mathrm{~mL}$ of ethanol) a FTO plate (TEC 15/2.2 mm thickness, Solaronix) and heating at $400^{\circ} \mathrm{C}$ for $15 \mathrm{~min}$. The $\mathrm{TiO}_{2}$ sensitized photoanode and $\mathrm{Pt}$ counter electrode were assembled into a sealed sandwich-type cell by a hot-melt ionomer film (Surlyn, $25 \mu \mathrm{m}$ thickness, Dyesol). The electrolyte solution, the commercially available Iolitech ES-0004 HP, containing 1butyl-3methylimidiazolium iodide, iodine, guanidiniumthiocyanate and tert-butylpyridine, in a mixture of valeronitrile and acetonitrile, with LiI $0.1 \mathrm{M}$ added where required, was inserted by vacuum backfilling. Then, the hole was sealed by using additional Surlyn patch and a cover glass and finally a conductive Agbased paint was deposed at the electrical contacts.

Photovoltaic measurements were recorded by means of AM 1.5 solar simulator equipped with a Xenon lamp (LOT-ORIEL LS 0106). The power of incoming radiation, set at $100 \mathrm{~mW} / \mathrm{cm}^{2}$, was checked by a piranometer. $J-V$ curves were obtained by applying an external bias to the cell and measuring the generated photocurrent with a Keithley model 2400 digital sourcemeter, under the control of dedicated LabTracer 2.0 software. A black shading mask was employed to avoid the overestimation of the measured parameters.

\subsection{Computational details}

The ground state equilibrium geometries of the isolated compounds were optimized in vacuum using the B3LYP exchange-correlation (xc) functional ${ }^{28}$ and the 6-31G* basis set. ${ }^{29}$ The UV-Vis absorption spectra of the dyes in solution were simulated by TDDFT calculations with the Coulomb-attenuating B3LYP (CAM-B3LYP) method $^{30}$ and a $6-31 \mathrm{G}^{*}$ basis set. Solvent (Ethanol, EtOH) effects were included by the conductor-like polarizable continuum model (C$\mathrm{PCM})^{31}$ as implemented in GAUSSIAN 09. ${ }^{32}$ In order to determine the frontier orbital energies and the corresponding electronic distribution, we performed single point calculations at the B3LYP/6-31G* level in solution.

\section{Results and Discussion}

The synthetic approach to these single donor (CARTHIOHX) and double donor (CAR-TPA) metal-free organic sensitizers involves Miyaura borylation, Suzuki and Knoevenagel reactions and the synthetic routes are outlined in schemes 2 and 3. Initially, base catalyzed $\mathrm{C}-\mathrm{N}$ bond formation was performed between carbazole and 4-fluorobenzaldehyde and the corresponding product subjected to bromination. Then by following palladium(0) catalyzed Suzuki coupling reaction, either donor TPA boronic acid or thiophene boronic acid have been connected to carbazole at 2, 7 positions. Finally, anchoring as well as electron acceptor group was introduced by reacting either $\mathbf{4}$ or $\mathbf{5}$ with cyanoacetic acid via Knoevenagel condensation leading to CAR-TPA and CAR-THIOHX. Detailed reaction procedures have been discussed in the experimental section of this paper.

These two single and double donor metal-free organic sensitizers, CAR-THIOHX and CAR-TPA were fully characterized by vary spectroscopic methods and elemental analysis. Preliminary characterization of both sensitizers was done by using elemental analysis, ESI-MS, IR and ${ }^{1} \mathrm{H}$ NMR spectroscopies. Elemental analysis results were consistent with the assigned formulations. The mass spectra obtained by the ESIMS technique, the molecular ion peak was observed at $\mathrm{m} / \mathrm{z} 845\left[\mathrm{M}^{+}+\mathrm{Na}\right]$ and $670\left[\mathrm{M}^{+}\right]$corresponds to the presence of CAR-TPA and CAR-THIOHX respectively. Stretching frequencies in IR spectra at 1728 and $1624 \mathrm{~cm}^{-1}$ corresponds to the presence of carbonyl groups of CAR-TPA and CAR-THIOHX, respectively (see Supporting information).

UV-Vis electronic absorption spectra of CAR-TPA and CAR-THIOHX have been recorded in various solvents with different polarities and the spectra are illustrated in figure 1 . As can be seen in the figure 1, CARTPA and CAR-THIOHX exhibit prominent absorption peaks in the UV region, at about $300 \mathrm{~nm}$, which are assigned to $\pi-\pi *$ transitions. At longer wavelengths we observe other absorption signals, bands or shoulder of the $n-\pi *$ transitions, with low molar extinction coefficients. These may be attributed to the intramolecular charge transfer (ICT) transitions from the donor carbazole to the cyanoacrylic moieties. ${ }^{33-35}$ The strong solvent dependency, solvatochromism further suggest 


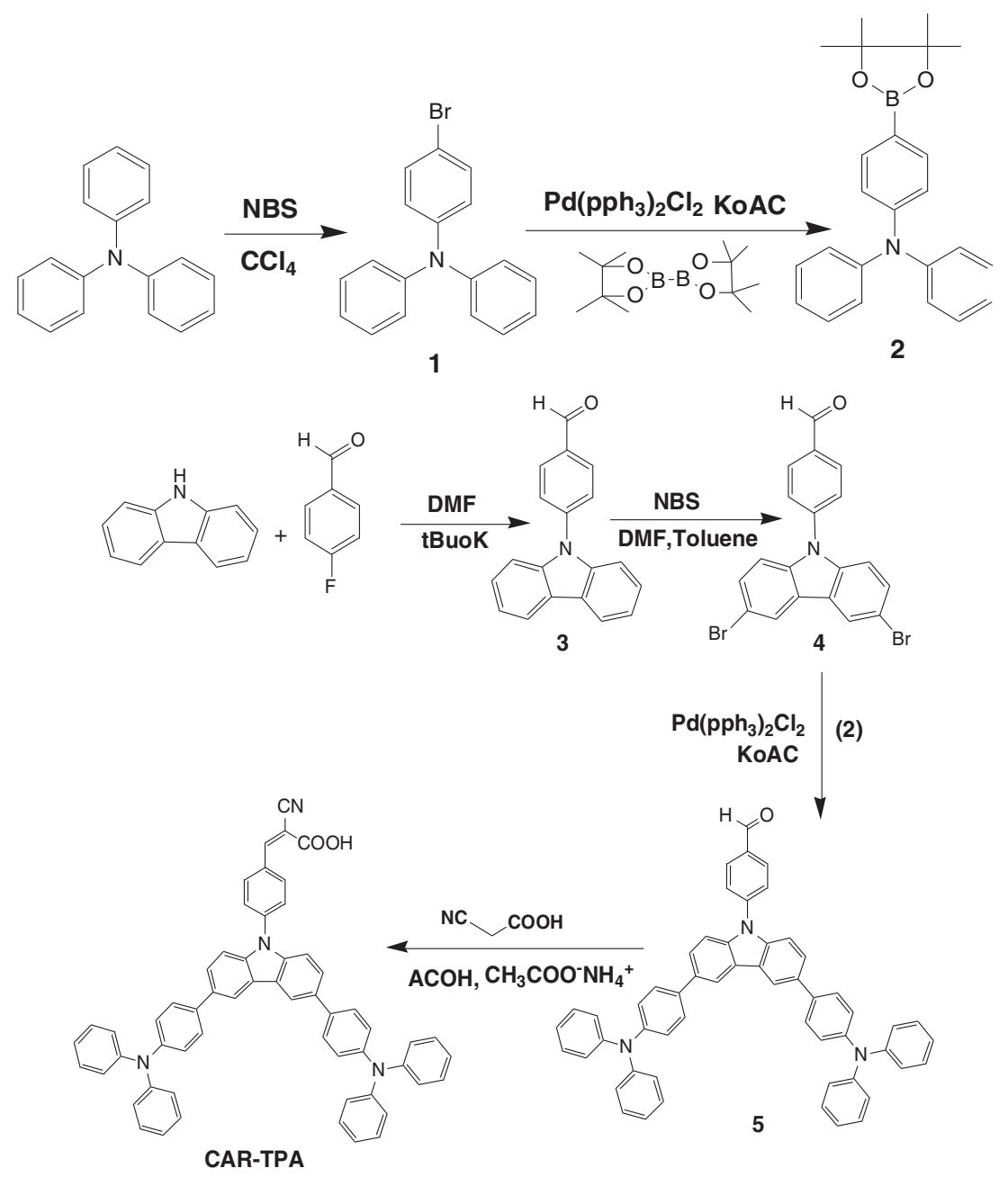

Scheme 2. Synthetic scheme of CAR-TPA.

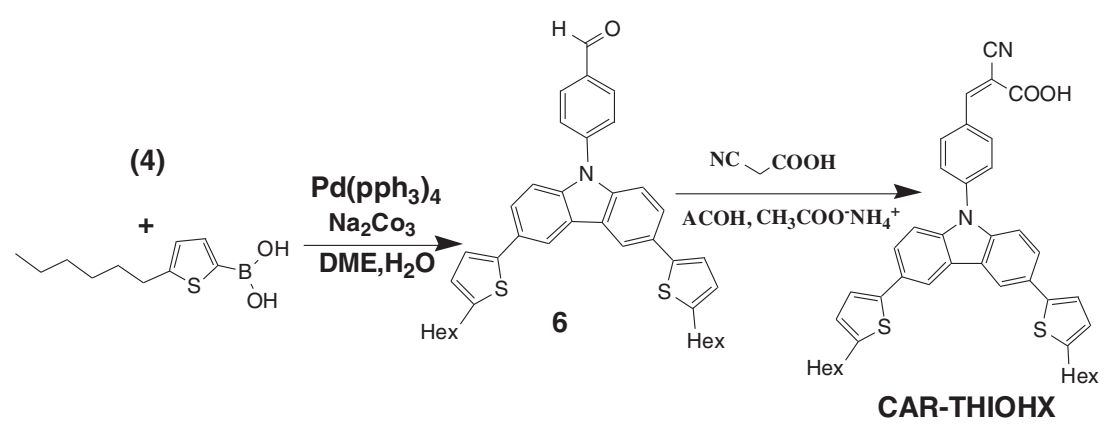

Scheme 3. Synthetic scheme of CAR-THIOHX.

the ICT character of the bands (table 1). As the polarity of the medium decreases (in low polar solvents DCM and toluene), the ICT band blue shifted (negative solvatochromism) and intensity increased to several fold presumably due to the aggregation tendency of both the dyes. Dyes aggregation is known to be a major problem which reduces the overall conversion efficiency of DSSC devices due to the reduced amount of absorbed light (caused by filtering effects) and intermolecular excited-state quenching. ${ }^{36-39}$ However, our experiments using low concentrated dye solutions also reveal the same behaviour that ruled out the aggregation of the dyes at those concentrations. The observed negative solvatochromism could also be attributed to the possible deprotonation of the carboxylic acid group. ${ }^{40-42}$

Fluorescence emission was also recorded in different solvents (toluene, THF, DCM, DMF and ethanol) and spectra in DCM are displayed in figure 2. The 

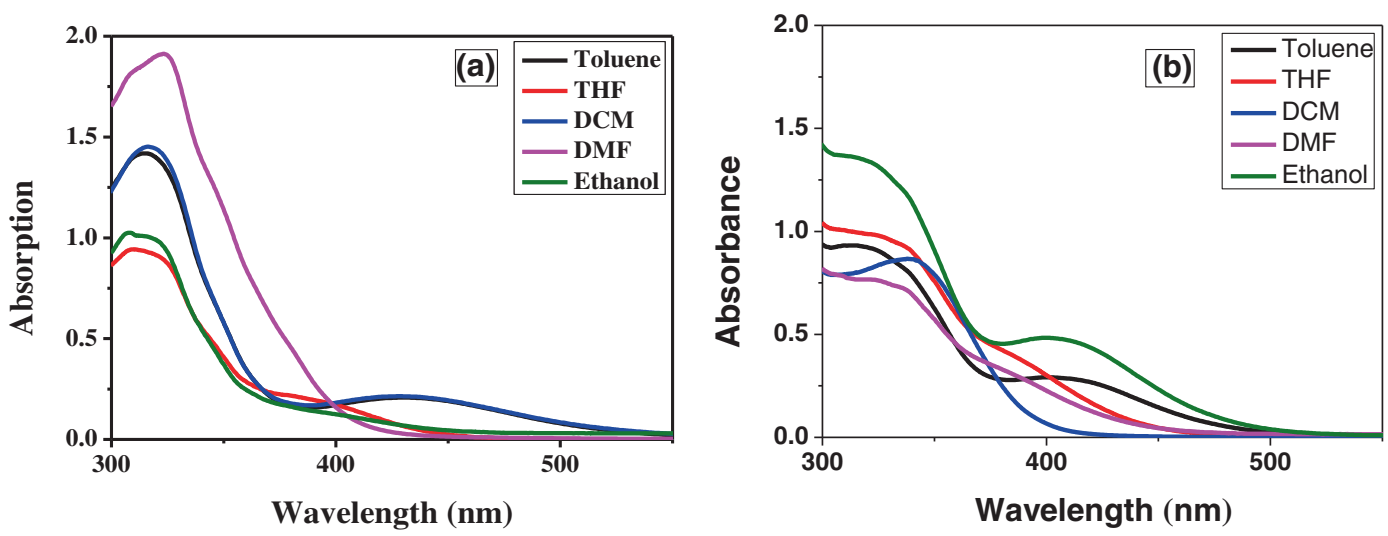

Figure 1. Absorption spectra of (a) CAR-THIOHX \& (b) CAR-TPA in different solvents.

Table 1. Absorption and emission maxima of CAR-THIOX and CAR-TPA in different solvents. ${ }^{\text {a }}$

\begin{tabular}{lcccc}
\hline Solvent & $\begin{array}{c}\text { CAR-THIOX } \\
\lambda_{\max }, \mathrm{nm},(\log \varepsilon)^{\mathrm{a}}\end{array}$ & $\begin{array}{c}\text { CAR-TPA } \\
\lambda_{\max }, \mathrm{nm},(\log \varepsilon)^{\mathrm{a}}\end{array}$ & $\begin{array}{c}\text { CAR-THIOX } \\
\lambda_{\mathrm{em}}, \mathrm{nm},(\phi)^{\mathrm{b}}\end{array}$ \\
$\begin{array}{lccc}\lambda_{\mathrm{em}}, \mathrm{nm},(\phi)^{\mathrm{b}} \\
\text { Toluene }\end{array}$ & $430(3.97)$ & $401(4.11)$ & 411 & 408 \\
$\mathrm{THF}$ & $395(3.90)$ & $388(4.08)$ & $411(0.08)$ & $408(0.08)$ \\
$\mathrm{CH}_{2} \mathrm{Cl}_{2}$ & $428(3.83)$ & $403(4.01)$ & $413(0.01)$ & $407(0.03)$ \\
$\mathrm{DMF}$ & $383(\mathrm{sh})$ & $338(3.94)$ & $415(0.04)$ & $410(0.04)$ \\
Ethanol & $390(3.72)$ & $325(3.92)$ & $416(0.05)$ & $412(0.07)$ \\
\hline
\end{tabular}

${ }^{\mathrm{a}}$ Error limits: $\lambda_{\max }, \pm 1 \mathrm{~nm}, \log \varepsilon, \pm 10 \%, \varepsilon$ in $\mathrm{M}^{-1} \mathrm{~cm}^{-1} \cdot{ }^{\mathrm{b}} \lambda_{\mathrm{em}}, \pm 1 \mathrm{~nm} ; \phi, \pm 10 \%$.

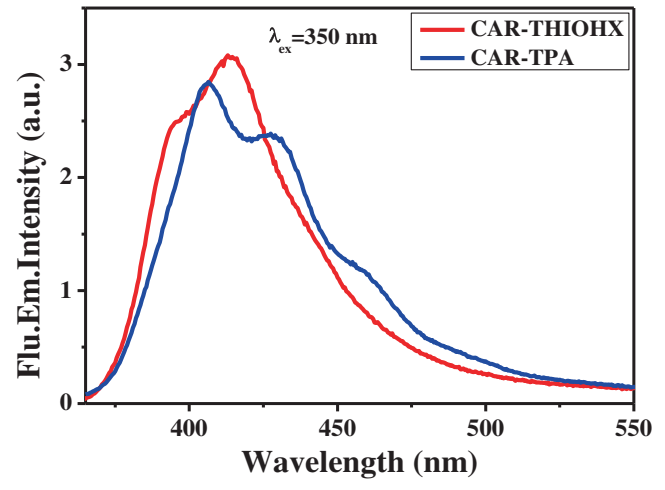

Figure 2. Emission spectra CAR-THIOHX and CARTPA in $\mathrm{CH}_{2} \mathrm{Cl}_{2}\left(\lambda_{\text {ex }}=350 \mathrm{~nm}\right)$.

wavelength of emission maxima and the fluorescence quantum yields are given in table 1 . These dyes exhibited moderate fluorescence quantum yields and large Stokes shift. From the table 1, one can easily conclude that the Stokes shift is due to the ICT from donor to acceptor. ${ }^{43}$ It was also found that the fluorescence emission maxima is red-shifted with increasing the solvent polarity (fluorescence solvatochromism) which further supports the excited state ICT nature (see Supporting information). Singlet state lifetimes of CAR-THIOHX and CAR-TPA in $\mathrm{CH}_{2} \mathrm{Cl}_{2}$ were estimated from the

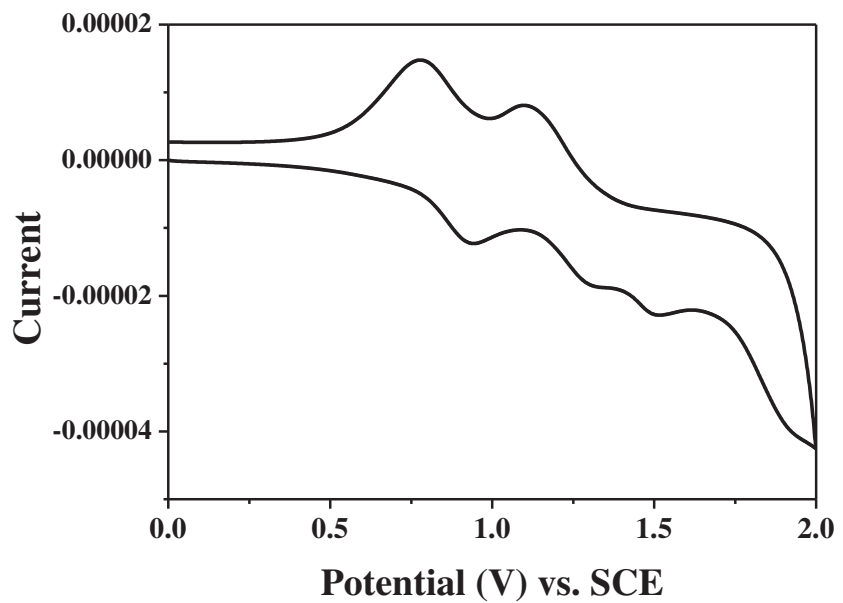

Figure 3. Cyclic voltammogram of CAR-TPA in $\mathrm{CH}_{2} \mathrm{Cl}_{2}$ solvent.

fluorescence decay curves $\left(\lambda_{\text {ex }} 301 \mathrm{~nm}\right.$ and $\lambda_{\text {em }}$ at $415 \mathrm{~nm}$ ) and found to be 2.42 and $1.66 \mathrm{~ns}$ respectively (see Supporting information).

For efficient electron injection, LUMO or oxidation potential of a dye sensitizer should be above the conduction band edge of $\mathrm{TiO}_{2}$ and similarly for efficient dye regeneration, HOMO of a dye sensitizer should lie below the energy level of redox system (for example iodine/iodide). ${ }^{44}$ In order to evaluate thermodynamic 
Table 2. Electrochemical data of CAR-THIOX and CAR-TPA in $\mathrm{CH}_{2} \mathrm{Cl}_{2}$.

\begin{tabular}{lcccc}
\hline \multirow{2}{*}{ Dye } & \multicolumn{2}{c}{$\mathrm{E}_{1 / 2}, \mathrm{~V}$ vs. SCE } & & \\
\cline { 2 - 3 } & $\mathrm{Ox}$ & $\mathrm{Red}$ & $\mathrm{E}_{0-0}, \mathrm{eV}^{\mathrm{b}}$ & $\mathrm{E}_{\mathrm{ox}}{ }^{* \mathrm{c}}$ \\
\hline CAR-THIOX & 1.90 & -1.42 & 2.95 & -1.05 \\
CAR-TPA & $0.85,1.20$, & $-1.10,-1.81$ & 3.09 & -1.59 \\
& $1.50,1.91$ & & & \\
\hline
\end{tabular}

${ }^{\mathrm{a} E r r o r ~ l i m i t s: ~} \mathrm{E}_{1 / 2} \pm 0.03 \mathrm{~V}, 0.1 \mathrm{M}$ TBAP; Glassy carbon working electrode, Standard calomel electrode is reference electrode, Pt electrode is auxillary electrode. ${ }^{\mathrm{b}}$ Calculated from the intersection point of absorption and emission spectra. Error limits, $\mathrm{E}_{0-0}= \pm 0.05 \mathrm{eV}$. ${ }^{\mathrm{c}}$ Calculated from the equation $\mathrm{E}_{\mathrm{ox}}^{*}=\mathrm{E}_{\mathrm{ox}}-\mathrm{E}_{0-0}$.

feasibility of the electron transfer process in these sensitizers and to assess the energy levels cylic voltammetric experiments were carried out. Cyclic voltammogram of CAR-TPA obtained by this technique is shown in figure 3 and the redox potentials for both dyes are shown in table 2. Both the sensitizers exhibit either reversible or quasi-reversible oxidation or reduction processes. The oxidation of CAR-TPA has four one-electron peaks. The first two reversible oxidation peaks belong to triphenyl moiety. The third irreversible oxidation at $1.51 \mathrm{~V}$ vs SCE belongs to carbazole moiety, ${ }^{34}$ whereas irreversible oxidation of CAR-THIOHX appeared at $1.90 \mathrm{~V}$. The reduction of CAR-TPA and CAR-THIOHX takes place at -1.10 and $-1.42 \mathrm{~V}$ vs. SCE, respectively. The first reduction potential of CAR-THIOHX exhibits positive shift compared to CAR-TPA, which might be due to the more electron releasing hexyl groups than the triphenyl groups. These measurements further suggest that the excited state oxidation potential $\left(\mathrm{E}_{\mathrm{ox}}^{*}\right)$ is more negative than the $\mathrm{TiO}_{2}$ conduction band edge $(-0.8 \mathrm{~V} \text { vs } \mathrm{SCE})^{45}$ and $\mathrm{E}_{\mathrm{ox}}$ energy level is more positive than the redox potential of iodine/iodide system $(0.2 \mathrm{~V} \text { vs SCE })^{46}$ for these dyes, allowing for working DSSC devices.

\subsection{Theoretical investigation}

In order to obtain insight into the effect of differing donor groups (on carbazole scaffold) on the electronic, optical and geometrical properties of CAR-THIOHX and CAR-TPA, these two dyes have been theoretically modeled, the optimized structures are shown in figure 4 . We note that both dyes have a similar structure. The carbazole plane is $47^{\circ}$ twisted with respect to the phenyl ring bonded at the N9 position. ${ }^{34}$ The strong deviation from the planarity between the carbazole donor and the phenyl-bridge and the cyanoacrylic acid group hinders the conjugation along the dye backbone, thus leading to an increase of the band gap and a less extended absorption spectra toward the visible region.

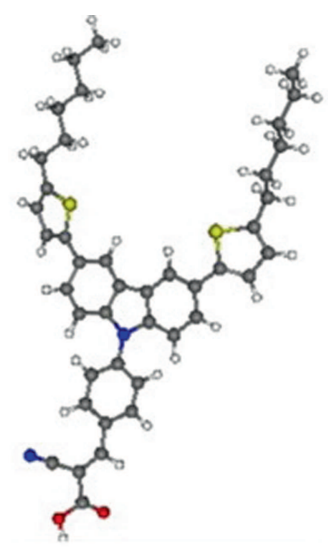

CAR-THIOHX

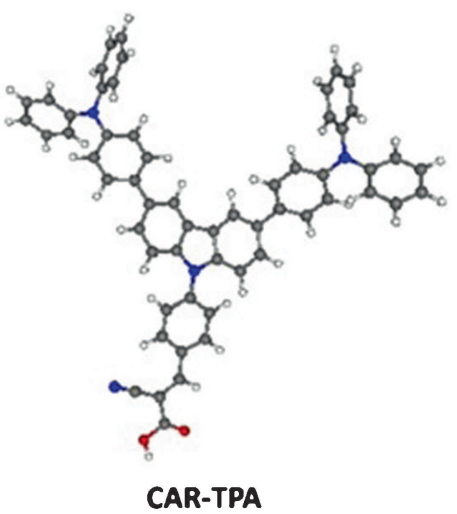

Figure 4. Optimized geometries of CAR-THIOHX and CAR-TPA sensitizers.

The isodensity plot of the HOMO and LUMO molecular orbitals of both CAR-THIOHX and CAR-TPA dyes, obtained at B3LYP/6-31G* level of theory, is shown in figure 5, while their energy level are reported in table 3. Both the dyes show a strong 'push-pull' character; the HOMO is localized on the main primary donor carbazole as well as on auxiliary donor either thiophene or triphenylamine, while the LUMO mainly localized on the acceptor cyanoacrylic acid group. The HOMO localization in the outer molecular region should ensure the exposure of the oxidized dye, generated after electron injection into the semiconductor, to the electrolyte redox couple, therefore favoring rapid regeneration of the oxidized sensitizer. The LUMO distribution close to the anchoring group enhances the orbital overlap with the titanium conduction band states, which is considered an essential requirement for efficient charge injection process. ${ }^{47}$ Interestingly, these two dyes show only slight differences in the LUMO energies (table 3), due to the fact that we have the same anchoring group. On the other hand, we see a sizeable difference in the HOMO energy values, with the CAR-THIOHX dyes having a more 


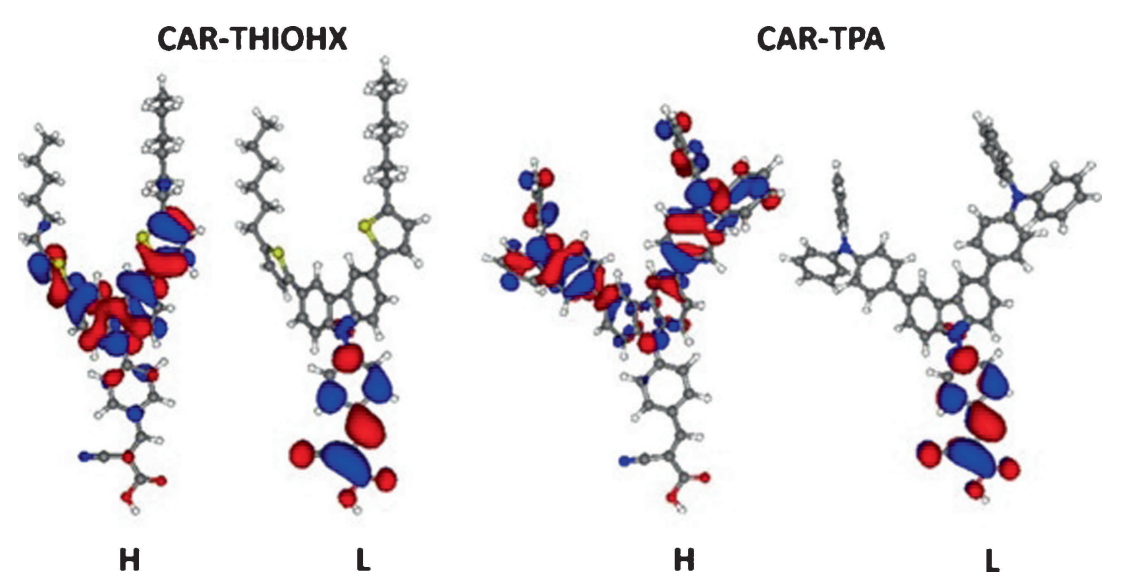

Figure 5. Isodensity plots of HOMO and LUMO involved in the excited states of CAR-THIOHX and CAR-TPA sensitizers.

Table 3. Energies (in eV) of the HOMO and LUMO molecular orbitals and energy gap $(\triangle \mathrm{E})$ of CAR-THIOHX and CAR-TPA sensitizers.

\begin{tabular}{lccc}
\hline Dye & HOMO $(\mathrm{eV})$ & LUMO $(\mathrm{eV})$ & $\Delta \mathrm{E}(\mathrm{eV})$ \\
\hline CAR-THIOHX & -5.26 & -2.67 & 2.59 \\
CAR-TPA & -4.95 & -2.66 & 2.29 \\
\hline
\end{tabular}

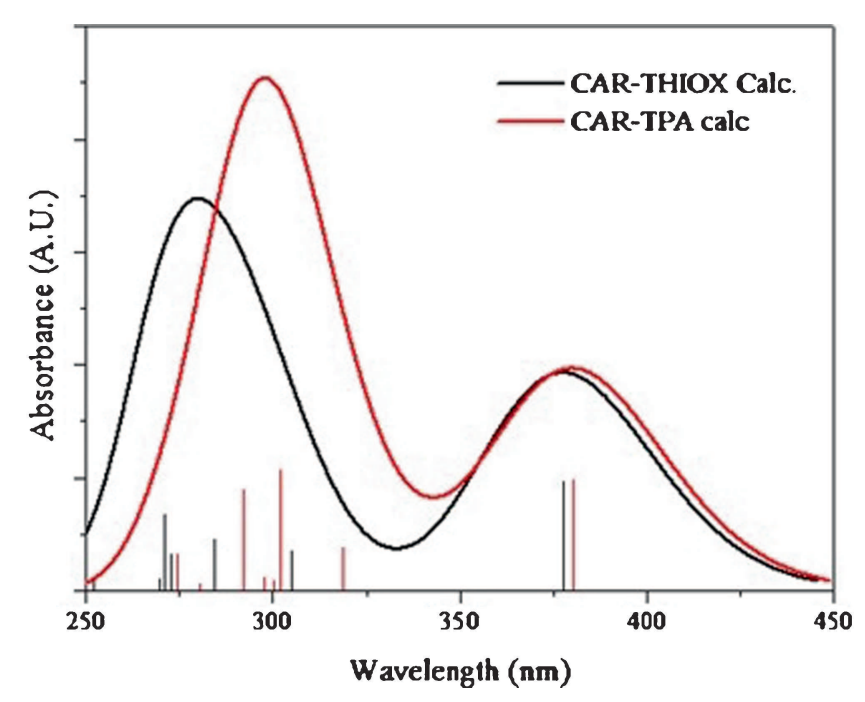

Figure 6. Simulated absorption spectra (CAM-B3LYP/6$31 \mathrm{G}^{*}$ in $\left.\mathrm{EtOH}\right)$ for both dyes.

stabilized HOMO level, leading to a higher band gap. In figure 6, we report the calculated absorption spectra of the both investigated dyes in ethanol solution. All the calculated electronic transitions energies, along with their oscillator strengths and molecular orbital compositions of dyes are summarized in supplementary information.

Both dyes show a similar absorption profile, with a single, low-lying transition, followed, at higher energy, by a series of additional transitions, constituting the $\pi-\pi^{*}$ absorption band at about $300 \mathrm{~nm}$. The main absorption band, as anticipated, has a strong ICT character, and it is constituted by an HOMO-LUMO transition ( $>50 \%$ ), (see Supplementary Information), leading to charge displacement from the carbazole donor to the cyanoacrylic anchoring group. We observe a slightly blue shifted absorption maxima $(377 \mathrm{~nm})$ for the CAR-THIOHX dye compared to the CAR-TPA $(380 \mathrm{~nm})$, with similar oscillator strengths. These values are in good agreement with the experimental data in ethanol solution (see figure 1 and table 1), even if in the experimental spectra the ICT absorption bands are less intense and appear only as a shoulder of the higher $\pi-\pi^{*}$ band in the UV region. The low extinction coefficient observed for the charge transfer transition can be related to the breaking of the conjugation between the carbazole moiety and the phenyl bridge, leading to a poor overlap between the HOMO and LUMO frontiers orbitals and thus to a less transition probability.

The fact that we observe only the tails of the absorption bands in the visible region, with extinction coefficient in the order of $10000 \mathrm{M}^{-1} \mathrm{~cm}^{-1}$, is detrimental for the photovoltaic performances of these dyes. With this low spectral extension (and therefore poor solar light harvesting) in the visible range one can expect only low photocurrent values. 

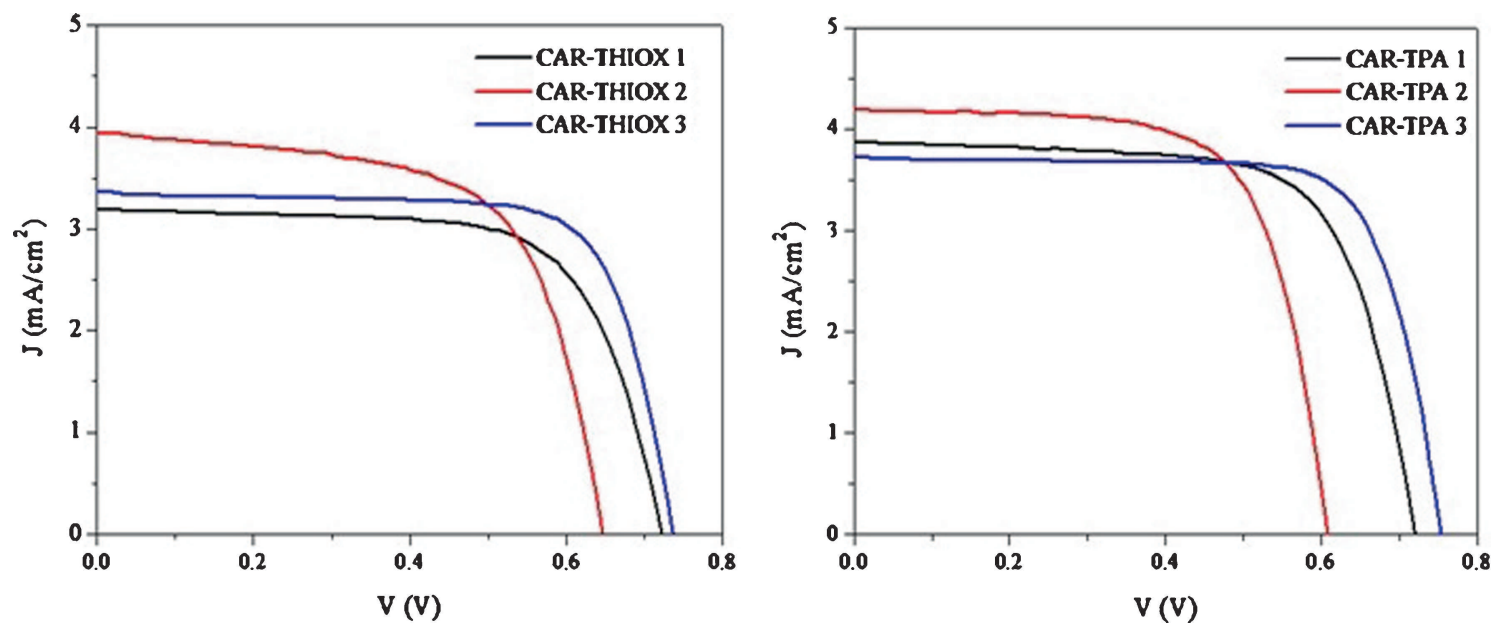

Figure 7. $J$ - $V$ curves of CAR-THIOX and CAR-TPA sensitized devices.

Table 4. Photovoltaic parameters for DSCs using an opeque $\mathrm{TiO}_{2}$ monolayer, measured under simulated AM 1.5. G, 1 SUN illumination

\begin{tabular}{lllllll}
\hline Dye & $\mathrm{TiO}_{2}$ & Additives & $J_{s c}\left(\mathrm{~mA} / \mathrm{cm}^{2}\right)$ & $V_{o c}(\mathrm{mV})$ & $f f$ & $\eta(\%)$ \\
\hline CAR-THIOHX-1 & Opaque & - & 3.19 & 722 & 0.69 & 1.58 \\
CAR-THIOHX-2 & Opaque & LiI 0.1M & 3.93 & 646 & 0.64 & 1.62 \\
CAR-THIOHX-3 & Trans+SL & - & 3.36 & 736 & 0.74 & 1.83 \\
CAR-TPA -1 & Opaque & - & 3.87 & 720 & 0.70 & 1.94 \\
CAR-TPA -2 & Opaque & LiI 0.1M & 4.19 & 610 & 0.68 & 1.75 \\
CAR-TPA -3 & Trans+SL & - & 3.72 & 755 & 0.76 & 2.12 \\
\hline
\end{tabular}

aError limits: $J_{S C}: \pm 0.20 \mathrm{~mA} / \mathrm{cm}^{2}, V_{O C}= \pm 30 \mathrm{mV}$, ff $= \pm 0.03$.

\subsection{Photovoltaic measurements}

Finally, the photovoltaic performances of CARTHIOHX and CAR-TPA have been evaluated in devices employing the iodine/iodide redox system. Ethanol:THF (9:1 v/v) solution has been utilized for grafting the sensitizers on to nanocrystalline $\mathrm{TiO}_{2}$ surface. Figure 7 illustrates photovoltaic response of the constructed DSSCs of both CAR-TPA and CARTHIOHX sensitizers which are investigated under various experimental conditions, while the PV parameters are reported in table 4 . In all the cases, the Chenodeoxycholic acid, CDCA, was employed as a co-adsorbent in the dye solution to minimize the aggregation of the dyes on the $\mathrm{TiO}_{2}$ surface. In the first test, an opaque $\mathrm{TiO}_{2}$ layer was used. The CAR-TPA sensitizer has shown better power conversion efficiencies compared to the CAR-THIOHX sensitizer, due to the higher photocurrents developed by the CAR-TPA dye, while similar values of $\mathrm{V}_{\text {oc }}$ and $\mathrm{FF}$ are measured. This is probably motivated by presence of the triphenylamine auxiliary donor moiety, enhancing the charge transfer directionality toward the acceptor. In both cases, anyway, we noted that the less extended absorption spectra and the competition with the $\mathrm{I}^{-} / \mathrm{I}_{3}^{-}$based electrolyte solution for the light absorption, limit the photocurrent production and thus the photovoltaic performances of these dyes. In order to improve the photocurrent values, we tested the effect of the LiI additive $(0.1 \mathrm{M})$ in the redox electrolyte. It has been noted that $\mathrm{Li}$ ions are able to downshift the $\mathrm{TiO}_{2}$ conduction band, facilitating the charge injection process and then improving the generated photocurrent. ${ }^{48,49}$ As expected, we obtain a gain in the photocurrent generation $\left(3.93 \mathrm{~mA} / \mathrm{cm}^{2}\right.$ for CAR-THIOHX and $4.19 \mathrm{~mA} / \mathrm{cm}^{2}$ for CAR-TPA), but unfortunately the overall efficiency does not improve due to the strong reduction of the $\mathrm{V}_{\text {oc }}$ in the order of $80-100 \mathrm{mV}$. Finally, we have tested a $\mathrm{TiO}_{2}$ scattering layer in combination with a transparent film, in order to improve the efficiency. In these conditions we obtained the best results, with power conversion efficiency of 2.12 and $1.83 \%$ for respectively CAR-TPA and CARTHIOHX dyes. In any case, the obtained improvements of the overall efficiency is quite low, in the order of $10-15 \%$, due to the still low $\mathrm{J}_{\mathrm{sc}}$ values. 
On the other hand, the $\mathrm{V}_{\mathrm{oc}}$ and $\mathrm{FF}$ values are satisfactory, testifying to the good potential of this class of sensitizers, once the light harvesting power will be increased through a careful selection of suitable donor and $\pi$-bridge moieties. The low efficiency of these sensitizers is probably due to the poor absorption properties in the visible region. If the absorption of these sensitizers push towards visible region then one can expect good efficiency. This can be achieved by introducing more extended $\pi$-conjugated groups in its molecular structure.

\section{Conclusions}

In conclusion, we have designed, synthesized and characterized two new sensitizers based on carbazole scaffold having one or two donors in its molecular structure. Photophysical and electrochemical properties have revealed that these sensitizers are potential candidates for DSSC applications. On the other hand, caused by the narrow absorption in visible region, the overall conversion efficiency is found to be low due to the poor photocurrent, $J_{S C}$. Theoretical investigation has shown that the poor light absorption in the visible region depend on the geometry of the two dyes, having $\sim 50^{\circ}$ twist between the carbazole donor plane and the phenyl bridge, leading to the 'breakout' of the conjugation along the dyes backbone and thus to less extended and intense absorption spectra. Though only moderate photovoltaic efficiencies were obtained, these two-donor carbazole-based dyes can be considered as a promising class of sensitizers, underlining once again the key importance of the selection of optimized $\pi$-bridge moieties for organic dyes. Studies towards increasing the DSSC performance of the carbazole dyes are underway in our laboratory.

\section{Acknowledgements}

The authors are thankful to the joint DST-EU project 'ESCORT' (FP7-ENERGY-2010, contract no. 262910) for the financial support of this work. JK thanks CSIR for senior research fellowship.

\section{References}

1. Ahmed S, Gullen G, Kavan L, Gratzel $M$ and Nazeeruddin M K 2013 Energy Environ. Sci. 63439

2. Zhang Z, Xu B, Su J, Shen L, Xie Y and Tian H 2011 Angew. Chem. Int. Ed. 5011654

3. Kim J Y, Lee K, Coates N E, Moses D, Nguyen T -Q, Dante M and Heeger A J 2007 Science $\mathbf{3 1 7} 222$
4. Kim H N, Guo Z Q, Zhu W H, Yoon J and Tian H 2011 Chem. Soc. Rev. 4079

5. Zhang S, Yang X, Numata Y and Han L 2013 Energy Environ. Sci. 61443

6. O’Regan B and Gratzel M 1991 Nature 353737

7. Giribabu L, Kanaparthi R K and Velkannan V 2012 Chem. Rec. 12306

8. Kanaparthi R K, Kandhadi J and Giribabu L 2012 Tetrahedron 688383

9. Mishra A, Fischer M K R and Bauerle P 2009 Angew. Chem. Int. Ed. 482474

10. Hum J -H, Baranhoff E, Kessler F, Moehl T, Ahmad S, Bessho T, Marchioro A, Ghadiri E, Moser J -E, Yi Ch, Nazeeruddin M K and Gratzel M 2012 Nature Commun. 31

11. Wang H -Y, Liu F, Xie L -H, Tang C, Peng B, Huang W and Wei W 2011 J. Phys. Chem. C 1156961

12. Ikeda N and Miyasaka T A 2005 Chem. Commun. 1886

13. Wang Z S, Koumura N, Cui Y, Takahashi M, Sekiguchi H, Mori A, Kubo T, Furube A and Hara K 2008 Chem. Mater. 203993

14. Koumura N, Wang Z -S, Mori S, Miyashita M, Suzuki E and Hara K 2006 J. Am. Chem. Soc. 12814256

15. Shen P, Tang Y, Jiang S, Chen H, Zheng X, Wang X, Zhao B and Tan S 2011 Org. Electron. 12125

16. Liu J, Yang X, Islam A, Numata Y, Zhang S, Salim N T, Che H and Han L 2013 J. Mater. Chem. A 110889

17. Ooyama Y, Yamaguchi N, Imae I, Komaguchi K, Oshita J and Harima Y 2013 Chem. Commun. 492548

18. Venkateswararao A, Justin Thomas K R, Lee C -P and Ho K -C 2013 Tetrahedron Lett. 543985

19. Yang C -H, Lin W -C, Wang T -L, Shieh Y -T, Chen W -J, Liao S -H and Sun Y -K 2011 Mater. Chem. Phys. 130635

20. Baheti A, Singh P, Lee C -P, Thomas J K R and Ho K -C. 2011 J. Org. Chem. 764910

21. Marotta G, Anil Reddy M, Singh S P, Islam A, Han L, De Angelis F, Pastore M and Chandrasekharam M 2013 ACS Appl. Mater. Interfaces 59635

22. Purification of Laboratory Chemicals $2003 \mathrm{~W}$ L F Armango and Ch L L Chai (Eds.) (NewYork: Butterworth Heinemann)

23. Shi L, Zhu D, He Q, Li Y, Chen Y, Sun Y, Fu Y, Wen D, Cao H and Cheng J 2012 J. Mate. Chem. 2211629

24. Bacher E, Bayerl M, Rudati P, Reckefess N, Muller, C D, Meerholz K and Nyuken O 2005 Macromolecules 38 1640

25. Zhang L, Zhang S, Yin L, Ji Ch, Li K, Li Y and Wang Y 2013 New J. Chem. 37632

26. Hu B, Zhuge F, Peng S, Chen X, Pan L, Yan Q and Li R -W 2012 J. Mater. Chem. 22520

27. Wu W, Yang J, Hua J, Tang J, Zhang L, Long Y and Tian H 2010 J. Mater. Chem. 201772

28. Becke A D 1983 J. Chem. Phys. 981372

29. Binkley J S A, Pople J and Hehre W J 1980 J. Am. Chem. Soc. 102939

30. Yanai T, Tew D P and Handy N C 2004 Chem. Phys. Lett. 39351

31. Cossi M, Rega N, Scalmani G and Barone V 2003 J. Comput. Chem. 24669

32. Frisch M J, Trucks G W, Schlegel H B, Scuseria G E, Robb M A, Cheeseman J R, Scalmani G, Barone V, Mennucci B, Petersson G A. et al. Gaussian; Gaussian Inc., Wallingford CT 2009 
33. Srinivas K, Yesudas K, Bhanuprakash K, Rao V J and Giribabu L 2009 J. Phys. Chem. C 11320117

34. Srinivas K, Kumar Ch R, Reddy M A, Bhanuprakash K, Rao V J and Giribabu L 2011 Syn. Metals 16196

35. Song J, Zhang F, Li C, Liu W, Li B, Huang Y and Bo Z 2009 J. Phys. Chem. C 11313391

36. Liu D, Fessenden R W, Hug G L and Kamat P V 1997 J. Phys. Chem. B $\mathbf{1 0 1} 2583$

37. Tatay S, Haque S A, O'Regan B, Durrant J R, Verhees W J H, Kroon J M, Vidal-Ferran A, Gavina $\mathrm{P}$ and Palomares E 2007 J. Mater. Chem. 173037

38. Wang Z-S, Cui Y, Dan-oh Y, Kasada C, Shinpo A and Hara K 2007 J. Phys. Chem. C 1117224

39. Pastore M and De Angelis F 2010 ACS Nano 4556

40. Yen Y -S, Hsu Y -C, Lin J T, Chang C -W, Hsu C -P and Yin D -J 2008 J. Phys. Chem. C 11212557

41. Hagberg D P, Edvinsson T, Marinado T, Boschloo G, Hagfeldt A and Sun L 2006 Chem. Commun. 2245
42. Huang $\mathrm{S}-\mathrm{T}$, Hsu $\mathrm{Y}-\mathrm{C}$, Yen $\mathrm{Y}-\mathrm{S}$, Chou H H, Lin J T, Chang C -W, Hsu C -P, Tsai C and Yin D -J 2008 J. Phys. Chem. C 11219739

43. Lin J T, Chen P-C, Yen Y -S, Hsu Y -C, Chou H -H and Yeh M -C P 2009 Org. Lett. 1197

44. Geiger T, Kuster S, Yum J -H, Moon S -J, Nazeeruddin M K, Gratzel M and Nuesch F 2009 Adv. Funct. Mater. 192720

45. Chen Y -S, Li C, Zeng Z -H, Wang W -B, Wang X -S and Zhang B -W 2005 J. Mater. Chem. 151654

46. Hagfeldt A and Gratzel M 1995 Chem. Rev. 95 49

47. Campbell W M, Burrell A K, Officer D L and Jolley K W 2004 Coord. Chem. Rev. 2481363

48. Redmond G and Fitzmaurice D 1993 J. Phys. Chem. 97 1426

49. Fredin K, Nissfolk J, Boschloo G and Hagfeldt A 2007 J. Electroanal. Chem. 60955 